\title{
Application of Polymeric Nanocomposites and Carbon Fiber Composites in the Production of Natural Gas Reservoirs
}

\author{
Gilberto João Pavani, ${ }^{1}$ Sérgio Adalberto Pavani, ${ }^{2}$ and Carlos Arthur Ferreira ${ }^{3}$ \\ ${ }^{1}$ Instituto Federal de Educação, Ciência e Tecnologia do Rio Grande do Sul, Avenida São Vicente 785, 95180-000 Farroupilha, Brazil \\ ${ }^{2}$ Universidade Federal de Santa Maria, Avenida Roraima 1000, Prédio 5, 97105-900 Santa Maria, RS, Brazil \\ ${ }^{3}$ LAPOL, Universidade Federal do Rio Grande do Sul, Avenida Bento Goncalves 9500, 91501-970 Porto Alegre, RS, Brazil
}

Correspondence should be addressed to Gilberto João Pavani; gilberto.pavani@farroupilha.ifrs.edu.br

Received 26 May 2015; Revised 4 August 2015; Accepted 11 August 2015

Academic Editor: Sesha Srinivasan

Copyright (C) 2015 Gilberto João Pavani et al. This is an open access article distributed under the Creative Commons Attribution License, which permits unrestricted use, distribution, and reproduction in any medium, provided the original work is properly cited.

\begin{abstract}
This research work is about the experimental analysis of the mechanical behavior of reservoirs for storage of compressed natural gas (CNG) consisting of a nanopolymeric liner coated with carbon fiber preimpregnated with epoxy resin applied by filament winding (FW). It addresses technical solutions adopted to optimize the reservoir as reinforcement with fiber, the process of healing and thermal analysis, as well as the hydrostatic testing to verify its resistance to the pressure required for CNG storage. Different nanoclays were incorporated to the polymer aiming to increase the strength of the liner and to reduce the thickness of its wall and the final weight of the reservoir as well as decreasing gas permeability. The obtained results were the basis for proposing an adaptation of the equation traditionally used for the dimensioning of the wall thickness of metallic pressure vessels to determine the number of layers needed to endure any internal pressure to which the reservoir is subjected. They indicate that the used methodology enables the production of pressure vessels for the storage of CNG, according to the ISO 11439:2013 Standard.
\end{abstract}

\section{Introduction}

Natural gas is considered the fossil fuel with the lowest emissions of carbon dioxide, with low emission of pollutants and waste from the combustion process [1], allowing it to be efficiently used in internal combustion engines [2].

The main disadvantages presented by natural gas as an automotive fuel are the high cost of compression and the weight of the steel reservoir for transport and storage [3].

The use of reservoirs fabricated with nonmetallic material aims to reduce the inert load present in vehicles fueled by compressed natural gas (CNG), allowing fuel saving and the increase of the engine's life, as well as reducing the emission of pollutants.

This type of reservoir consists of a liner, whose primary function is gas impermeability, and reinforcement, whose main function is to resist the pressure of work.

The polymeric liner adds to the reservoir characteristics such as light weight, resistance to pressure and impact, corrosion protection, and durability [4] and is usually made of rotomolded polyethylene (PE) due to the low cost of production. The PE is the most widely used resin for rotational molding due to low cost, chemical inertness, ease of processing, and mechanical properties [5] that can be improved by cross-linking or by the addition of nanoclays.

Rotational molding is suited for production of large and dimensionally stable hollow parts, with superficial finish comparable to injection molding. Additionally, as pointed out by Crawford and Throne [6], it has lower mold costs.

The high pressure of vehicular CNG storage requires the polymeric liner to be coated with carbon fiber, using the process of filament winding (FW) because of its low production cost, high productivity, and high reliability, besides providing nearly isotropic properties to the final product [7].

The liner is used as a mandrel in the FW process, allowing the arrangement of the fibers for structural reinforcement at various angles and patterns in the direction of the main solicitation by overlapping layers composed of nongeodesic winding and circumferential winding. 
Based on the concept presented above, the Thiokol company has had success in the storage of hydrogen [8], but the main contribution of this work is the addition of nanoclay to the polyethylene blend, aiming to increase the polymeric liner's resistance to pressure as well as this polymer's gas permeability.

ISO 11439:2013 [9] covers cylinders of any seamless steel, seamless aluminium alloy, or nonmetallic material construction, using any design or method of manufacture suitable for the specified service conditions.

Thus, pressure vessels for CNG must conform to the ISO 11439:2013 Standard's Method, which specifies the requirements for the validation of $\mathrm{CNG}$ storage reservoirs for automotive vehicles, including buses and trucks.

The standard classifies as CNG-4 cylinders those produced entirely with nonmetallic materials, using appropriate manufacturing methods for the service conditions for vehicular transport, such as the reservoirs in development.

In order to increase the liner's resistance to pressure, the addition of nanoclays to polyethylene was chosen, adopting the following actions to achieve the standard pressure:

(a) Analysis of possible failure on the existing liner.

(b) Analysis of possible failure in the composite coating.

(c) Adding more carbon fiber layers to satisfy the requirements of the standard.

Aiming to estimate the number of layers needed to endure any internal pressure to which the reservoir is subjected, an adaptation is proposed in the equation presented by Popov [10], having as base the hydrostatic tests' results made on reservoirs with one, two, and three layers of carbon fiber.

The proposed formula indicated that a fourth layer would meet the requirement of this standard, as calculated by linear regression and the equation proposed in this paper for calculating the number of layers for any internal pressure.

The obtained results indicate that the used methodology would allow the production of reservoirs for vehicular use classified as CNG-4, according to ISO 11439:2013, allowing a reduction of at least $60 \%$ (sixty percent) of the weight in relation to a steel cylinder.

\section{Materials and Methods}

2.1. CNG Reservoir. The polymeric liner in real scale $(\varnothing 225 \times$ $725 \mathrm{~mm}$ ), with capacity for 22 liters of water, was manufactured by rotational molding, with a blend of LDPE/HDPE, coated with carbon fiber preimpregnated with epoxy resin, developed in a previous study [11].

2.2. Filament Winding. The simulation of the application of the reinforcement layers by FW was performed with the software CADWind 2007, version 8271 (Material SA).

The liner was used as a mandrel, being coated with in successive layers composed of nongeodesic winding and circumferential winding at a $10^{\circ}$ angle which allows variation of the winding angle along a given section of the mandrel.

The layers were applied by a Kuka Roboter GmbH robot, type KR 140 L 100-2, for ensuring reliability and repeatability,

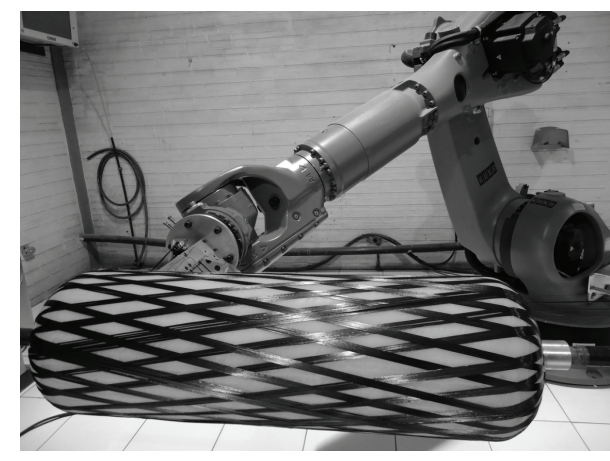

FIGURE 1: Nongeodesic winding.

shown in Figure 1, necessary characteristics to the reservoir in development that should store CNG.

The carbon fiber was applied at room temperature adopting as the cure cycle heating at $<3^{\circ} \mathrm{C}$ per minute to $90^{\circ} \mathrm{C}$ residence for 24 hours and cooling at $<3^{\circ} \mathrm{C}$ for a minute to $66^{\circ} \mathrm{C}$ before removal from the oven.

\subsection{Reservoir Characterization}

2.3.1. Hydrostatic Test. In that test, we used the Flutrol equipment (150 psi) with HBM $50 \mathrm{MPa}$ load cell, Spindler $8,60 \mathrm{~Hz}, \mathrm{HBM}$ Interface. The samples were pressurized at $0.1 \mathrm{MPa} / \mathrm{s}$ and the data was processed with the Catman 4.0 Professional software.

2.3.2. Differential Exploratory Calorimetric Analysis. The samples were removed from the reservoirs with one, two, and three layers, taking as reference a carbon fiber sample taken from the roll in use, to check whether the cure cycle was adequate.

The samples were heated at a rate of $10^{\circ} \mathrm{C} / \mathrm{min}$ from room temperature to $250^{\circ} \mathrm{C}$, with rapid cooling $\left(50^{\circ} \mathrm{C} / \mathrm{min}\right)$ to room temperature, and again heated to $250^{\circ} \mathrm{C}$.

The pieces of equipment used were DSC Q20 (TA Instruments) with nitrogen gas $\left(\mathrm{N}_{2} \mathrm{Up}\right)$ and graphs generated by Universal Analysis 2000 software, version 4.5 A, build 4.5.0.5, TA Instruments-Waters LLC.

The tensile testing of injection molded and rotomolded samples was carried out in the universal testing machine, aiming to select the best raw materials for the manufacturing of the liner regarding the mechanical strength.

The samples tested were as follows:

(i) Blends of polyethylene.

(ii) Blends of polyethylene with 5 weight $\%$ of Brazilian nanoclay.

(iii) Blends of polyethylene with 5 weight $\%$ of American nanoclay.

(iv) Blends of polyethylene with 5\% of XLPE.

(v) XLPE.

(vi) XLPE with 5 weight $\%$ of Brazilian nanoclay.

(vii) XLPE with 5 weight $\%$ of American nanoclay. 
Remarks are as follows:

(i) XLPE: ICORENE K1502 was from the company ICO Polymers.

(ii) Brazilian nanoclay: montmorillonite clay with granulometry of 74 microns was produced by the company Bentonisa S/A.

(iii) American nanoclay: montmorillonite Cloisite 30B clay was produced by the company Southern Clay Products.

(iv) These products were mixed manually to the blend of polyethylene and extruded in single screw equipment.

The rotomolded samples were ground in a bench mill of the MTC Robotics brand, from the injected mold design, and taken directly from rotomolded parts.

The injected samples were produced in a brand miniinjector, Thermo Scientific, model MiniJet II Haake, with a standardized mold. The samples were injected at $185^{\circ} \mathrm{C}$ with two tons of pressure, except for the XLPE that was injected at $205^{\circ} \mathrm{C}$.

Five samples of each raw material both machined and injected were subjected to a tensile test at $5,000 \mathrm{~mm} / \mathrm{min}$.

Tensile testing of carbon fiber preimpregnated with epoxy resin samples was conducted in the EMIC DL20000 brand universal testing machine, with a TRD26 load cell, TRD15 strain gauge, claws for polymeric films, and the MTest version 3.0 software, aiming to find the maximum tensile strength of a single strand of said fiber.

2.3.3. Oxygen Permeability Test. The test intended to measure the permeability of the liner to methane, but due to lack of equipment to measure the permeability, it verified the oxygen permeability which has compatible polarity and molecular diameter.

The test was performed with two groups of samples according to ASTM F 1927 (plates) [12] and ASTM D 3985 (film) [13].

The first group of samples consisted of hot pressed plates in the mold, cut $12 \mathrm{~cm}$ in diameter and machined to a thickness of $1 \mathrm{~mm}$ in the MTC milling machine.

Three samples were tested as follows:

(i) Blend of polyethylene.

(ii) Blends of polyethylene with 5\% weight of Brazilian nanoclay.

(iii) Blends of polyethylene with 5\% weight of American nanoclay.

The second group of samples, consisting of films of polyethylene blend with nanoclay, had the pellets extruded at $250 \mathrm{rpm}$ in twin screw corotating $\mathrm{MH}$-Colour-20-32-Lab, after heating in an oven at $80^{\circ} \mathrm{C}$ for 24 hours for drying.

\section{Results and Discussion}

Reservoirs with three layers hit the average pressure of 350 bar $\pm 5 \%$ when subjected to hydrostatic test but did not meet
TABLE 1: Relationship between layers, weight, and pressure.

\begin{tabular}{lcc}
\hline Layers & Weight $(\mathrm{kg})$ & Pressure (bar) \\
\hline 1 & $1,220 \pm 3 \%$ & 150 bar $\pm 5 \%$ \\
2 & $2,240 \pm 3 \%$ & 250 bar $\pm 5 \%$ \\
3 & $3,430 \pm 3 \%$ & 350 bar $\pm 5 \%$ \\
\hline
\end{tabular}

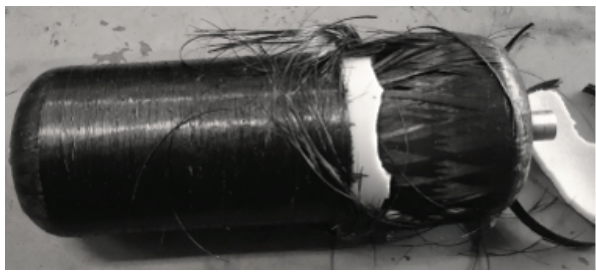

FIgURE 2: Reservoir destroyed.

the requirements of ISO 11439:2013 that determine the minimum pressure test for a CNG-4 reservoir as 2,25 times the working pressure, which is defined as 200 bar.

3.1. Hydrostatic Testing. Table 1 shows the average weight increase per layer and the average hydrostatic test results of the samples of liner coated with preimpregnated carbon fiber layers.

The calorimetric analysis by Differential Scanning Calorimetry indicates that the cure cycle for the preimpregnated carbon fiber with epoxy resin used in the reservoirs of one, two, and three layers was complete.

3.2. Fracture Liner. The fracture of the liner, in $80 \%$ (eighty percent) of the cases, regardless of the number of layers, occurred in the region near the tops due to lower wall thickness resulting from the manufacturing process by rotational molding, shown in Figure 2.

The simulation performed by Velosa et al. [14] indicated that the fracture occurred near the tops, a region of higher stress due to the action of the radial and the longitudinal stress, despite increased wall thickness.

In the case of the reservoir in development, the fracture also occurred near the tops, a region that has the lowest wall thickness, requiring adjustments to the project to increase the mechanical strength of the liner in the hydrostatic test.

However, careful control of the manufacturing process by rotomolding would maintain the continuity of the wall thickness of the polymeric reservoir, eliminating its significant reduction that causes premature rupture during hydrostatic testing. Furthermore, the addition of nanoclay increases the mechanical strength of the polyethylene blend constituting the reservoir and placing preimpregnated carbon fiber strips in the zone of concentration of the radial and longitudinal stresses results in increased resistance to pressure in said test.

3.3. Selection of New Materials for the Liner. In order to increase the liner's mechanical resistance and lower the nominal thickness of its wall, new materials were sought through tensile tests for its selection. 
TABLE 2: Results of tensile testing of candidate materials (N).

\begin{tabular}{lcr}
\hline Material & Rotomolded & Injected \\
\hline Blend PE & $143,84 \pm 32,03$ & $238,70 \pm 18,37$ \\
Blend PE with 5 wt\% of nanoclay, Brazilian & $137,80 \pm 11,38$ & $205,12 \pm 8,24$ \\
Blend PE with 5 wt\% of nanoclay, American & $140,74 \pm 6,25$ & $220,27 \pm 3,79$ \\
Blend PE with 5\% XLPE & $151,23 \pm 8,73$ & $222,46 \pm 5,06$ \\
XLPE & $125,52 \pm 4,07$ & $267,44 \pm 63,15$ \\
XLPE with 5 wt\% of nanoclay, Brazilian & $85,36 \pm 4,25$ & $364,08 \pm 30,72$ \\
XLPE with 5 wt\% of nanoclay, American & $60,06 \pm 4,74$ & $367,95 \pm 50,24$ \\
\hline
\end{tabular}

The tensile testing of such materials showed that the injected samples showed higher tensile strength than the rotomolded ones, that the addition of nanoclay increased tensile strength, and that American nanoclay (Cloisite 30B) showed better results than the Brazilian one because of it having more appropriate granulometry as observed in Table 2 .

The literature recommends a weight percentage of nanoclay between $1 \%$ and $5 \%$ [15] for the gas barrier effect, but numerous studies indicate values optimized around 2\% [16-18]. We opted for the limit value of 5\% [19-21] to verify the influence of the type of nanoclay on the barrier and mechanical behavior of the reservoirs so that later the optimized value of the amount of nanoclay would be deemed appropriate for the purposes of this search.

In the tensile test, we adopted the von Mises criterion for the flow of an ideally plastic material in a triaxial stress state $[22,23]$ :

$$
2(\sigma y)^{2}=(\sigma 1-\sigma 2)^{2}+(\sigma 2-\sigma 3)^{2}+(\sigma 3-\sigma 1)^{2},
$$

where $\sigma y=$ flow tension at rupture, $\sigma 1=$ circumferential tension: $\sigma c, \sigma 2=$ longitudinal tension: $\sigma l$, and $\sigma 3=$ radial tension: $\sigma r$.

Adjusting the equation,

$$
2(\sigma y)^{2}=(\sigma c-\sigma l)^{2}+(\sigma l-\sigma r)^{2}+(\sigma r-\sigma c)^{2} .
$$

In cylinders subjected to internal pressure, the expressions for $\sigma c, \sigma l$, and $\sigma r$ are

$$
\begin{aligned}
& \sigma c=\frac{p \cdot d}{2} \cdot t, \\
& \sigma l=\frac{p \cdot d^{2}}{\left(D^{2}-d^{2}\right)}, \\
& \sigma r=-\frac{p}{2},
\end{aligned}
$$

where $p$ is internal pressure in the cylinder, $D$ is external diameter of the cylinder, $d$ is inner diameter of the cylinder, and $t$ is wall thickness.

Replacing these values in (2) and evidencing " $p$ ” we have

$$
p=\frac{(4 \cdot \sqrt{(3)})}{3} \cdot \sigma y \cdot \frac{\left(t-t^{2} / D\right)}{(D \cdot \sqrt{(1-4 \cdot t)} / D)} .
$$

Equation (4) shows that the cylinder's burst pressure is directly proportional to the flow tension, whose value is close to the tensile resistance limit tension ( $\sigma r t)$ obtained in the tensile test.

Thus, the higher the value of $\sigma r t$, the greater the pressure supported by the cylinder in the hydrostatic test.

For Walters [23], do not use (4) to predict the burst pressure because $\sigma y$ differs from conventional yield stress $(\sigma e)$, obtained in the tensile test.

Therefore, in qualitative terms, it is possible to use the tensile test to select candidate materials for the manufacturing of CNG reservoirs.

3.4. Calculation of the Number of Layers of the Reservoir. The tensile testing of the carbon fiber preimpregnated with epoxy resin samples was carried out to find the maximum tensile strength of a single strand of fiber, allowing the calculation of the number of layers needed for any internal pressure that the reservoir is subjected to during hydrostatic testing.

In a cylindrical shell, there are two major strains:

(i) Longitudinal stress $(\sigma l)$ which tends to break the tops, being supported by the nongeodesic winding.

(ii) Circumferential stress $(\sigma c)$ which tends to break the side wall, being supported by circumferential winding.

For the design of a cylindrical reservoir, circumferential tension is used, because the longitudinal tension corresponds to half of this tension.

The tensile test conducted at IFRS resulted in an average tensile strength of $56.65 \mathrm{kgf} / \mathrm{mm}^{2} \pm 15 \%$ for one preimpregnated filament of fiber, corresponding to resistance to circumferential tension.

The tensile strength of the nongeodesic winding is calculated by multiplying the value obtained in the tensile test by $\sin \left(10^{\circ}\right)$, resulting in an average tensile resistance of $9.84 \mathrm{kgf} / \mathrm{mm}^{2}$ for one filament.

The value of the layer corresponds to the sum of the values, that is, $66.46 \mathrm{kgf} / \mathrm{mm}^{2}$.

The number of layers of a cylindrical reservoir can be calculated by tension caused by the internal pressure, according to (5) presented by Popov [10]:

$$
\sigma c=\frac{p \cdot r}{t},
$$


where $\sigma c$ is circumferential tension to the layer calculated from the value obtained in the tensile test in IFRS = $66.46 \mathrm{kgf} / \mathrm{mm}^{2}, p$ is internal pressure obtained in the hydrostatic testing for the three layers' reservoir $=3.57 \mathrm{kgf} / \mathrm{mm}^{2}$, $r$ is radius of the cylinder $=110 \mathrm{~mm}$, and $t$ is layer thickness $(\mathrm{mm})=$ ?

Evidencing “ $t$ ” in (5), we obtain

$$
t=\frac{p \cdot r}{\sigma c}
$$

where $t \sim 5.9 \mathrm{~mm}=6$ layers.

However, the experimental results suggest that $(*)$ must be adapted for coating in a preimpregnated carbon fiber composite as follows:

$$
t=\frac{p \cdot r}{k} \cdot \sigma c
$$

where $k$ is the material factor and $k=1$ for steel and $k=2$ for preimpregnated carbon fiber.

Recalculating the number of layers of a cylindrical reservoir in preimpregnated carbon fiber $(k=2)$ in $(*-1)$, we obtain the following result:

$$
t=\frac{p \cdot r}{k} \cdot \sigma c
$$

where $t \sim 2.95 \mathrm{~mm}=3$ layers, which corresponds to the experimental result.

As the main function of the liner is gas impermeability, its small contribution to resistance to circumferential stress $(\sigma c)$ is disregarded.

Therefore, to calculate the number of layers for the standard pressure of $459 \mathrm{bar}\left(4.59 \mathrm{kgf} / \mathrm{mm}^{2}\right)$, using $(*-1)$, we have the following result:

$$
t=\frac{p \cdot r}{k} \cdot \sigma c
$$

where $p$ is internal pressure required by international standard $=4.59 \mathrm{kgf} / \mathrm{mm}^{2}, r$ is radius of the cylinder $=110 \mathrm{~mm}, k$ is material factor for preimpregnated carbon fiber composite $=$ 2, $\sigma c$ is circumferential tension to the layer calculated from the value obtained in the tensile test in the IFRS = $66.46 \mathrm{kgf} / \mathrm{mm}^{2}$, and approximately $t=3.8 \mathrm{~mm}$ corresponding 4 layers.

The value coincides with the calculation by linear regression and the equation proposed for calculating the number of layers for any internal pressure (see $(*-1))$, while maintaining the advantage in comparison to the weight of the steel cylinders.

In order to obtain the necessary pressure to halve the volume of the reservoir, at room temperature, (6) is used as follows:

$$
P \cdot V=z \cdot n \cdot R \cdot T
$$

where $P=$ pressure $\left[\mathrm{Pa}=\mathrm{N} / \mathrm{m}^{2}\right] ; V=$ volume $\left[\mathrm{m}^{3}\right]$; $n=$ number of moles; $R$ (Universal Gas Constant) = $8.3144 \mathrm{Nm} /(\mathrm{mol} \cdot \mathrm{K}) ; T=$ absolute temperature $[\mathrm{K}] ; z=$ compressibility factor $(\mathrm{z})$.
The compressibility factor represents the ratio between the volume occupied by given mass of gas under certain conditions of pressure and temperature and the volume that this mass would occupy at the same conditions as if it was an ideal gas [24].

The compressibility factor varies with the composition, pressure, and temperature of the gas and can be calculated by the equation of state of Dranchuk and Abou-Kassem [25].

As the gas is the same and its temperature remains constant in the compression process, we have

$$
n=\frac{P 1 \cdot V 1}{z 1}=\frac{P 2 \cdot V 2}{z 2},
$$

where $P 1$ (usual storage pressure) $=220 \mathrm{bar}=22 \mathrm{MPa}, V 1=$ volume before compression $=1 \mathrm{~m}^{3}, z 1=0.73286=$ compressibility factor, $P 2=$ ?, $V 2=$ volume after compression $=$ $0.5 \mathrm{~m}^{3}, z 2=1,41458$, and $P 2=648 \mathrm{kgf} / \mathrm{cm}^{2}=636$ bar.

According to ISO 11439:2013, the hydrostatic test pressure of one CNG-4 reservoir is 2.25 times the working pressure, resulting in a 1.431-bar test pressure.

Calculating the number of layers of a cylindrical reservoir in preimpregnated carbon fiber, using $(*-1)$, we obtain the following result:

$$
t=\frac{p \cdot r}{k} \cdot \sigma c
$$

where $p$ (calculated hydrostatic test pressure $)=1.431$ bar $=$ $14.60 \mathrm{kgf} / \mathrm{mm}^{2}, r$ (radius of the cylinder) $=110 \mathrm{~mm}, k$ (material factor for preimpregnated carbon fiber composite) $=2, \sigma c$ (circumferential tension to the layer calculated from the value obtained in the tensile test in the IFRS) $=66.46 \mathrm{kgf} / \mathrm{mm}^{2}$, and $t=12,13 \mathrm{~mm}=12$ layers.

Equation $(*-1)$ indicates that a fourth layer of carbon fiber will meet the requirements of ISO 11439:2013, resisting the pressure of 495 bar for hydrostatic testing, maintaining the advantage in relation to the weight.

3.5. Gas Permeability. The oxygen permeability test was performed on two groups of samples: rotomolded plates and film, adopted as reference.

The result of the permeability in the tested sheets is as follows:

(i) Polyethylene blend: $13,660 \mathrm{~mL}\left(\mathrm{STP} / \mathrm{m}^{2} /\right.$ day) at $1 \mathrm{~atm}$ and $23^{\circ} \mathrm{C}$.

(ii) Blends of polyethylene with $5 \%$ weight of Brazilian nanoclay: $32,829 \mathrm{~mL}\left(\mathrm{STP} / \mathrm{m}^{2} /\right.$ day $)$ at $1 \mathrm{~atm}$ and $23^{\circ} \mathrm{C}$.

(iii) Blends of polyethylene with $5 \%$ weight of American nanoclay: $150,000 \mathrm{~mL}\left(\mathrm{STP} / \mathrm{m}^{2} /\right.$ day) at 1 atm and $23^{\circ} \mathrm{C}$ (detection limit of the equipment).

The high permeability shown by rotomolded samples nanoclays is due to the processing in a single screw extruder which did not allow the adequate shear and distribution of the clay particles.

The following samples were analyzed in films:

(i) Sample A: HDPE Blend (95\%), LDPE (5\%), and sodium nanoclay (no compatibilizer). 
TABLE 3: Oxygen permeability coefficient $\left(\mathrm{PO}_{2}\right)$ at $23^{\circ} \mathrm{C}$, dry.

\begin{tabular}{lccc}
\hline Sample & \multicolumn{2}{c}{$\mathrm{PO}_{2}\left(\mathrm{~mL}(\mathrm{STP}) \cdot \mu \mathrm{m} \cdot \mathrm{m}^{-2} \cdot \mathrm{day}^{-1} \cdot \mathrm{atm}^{-1}\right)$} \\
Average & $\begin{array}{c}\text { Individual } \\
\text { values }\end{array}$ \\
\hline $\begin{array}{l}\text { Sample A } \\
\text { Nanoclay sodium }\end{array}$ & 295.761 & $144.332 / 309.589 / 433.364$ & 49 \\
\hline $\begin{array}{l}\text { Sample B } \\
\text { Cloisite 15A }\end{array}$ & 40.258 & $36.284 / 44.232$ & 14 \\
\hline $\begin{array}{l}\text { Sample C } \\
\text { Cloisite 30B }\end{array}$ & 93.236 & $60.644 / 63.405 / 155.659$ & 58 \\
\hline
\end{tabular}

(ii) Sample B: HDPE Blend (95\%), LDPE (5\%), and Cloisite $15 \mathrm{~A}$ nanoclay.

(iii) Sample C: HDPE Blend (95\%), LDPE (5\%), and Cloisite 30B nanoclay.

The rates of oxygen permeability $\left(\mathrm{TPO}_{2}\right)$ were determined by coulometric method according to standard D398505 (ASTM, 2010), in OXTRAN equipment, model 2/20, from the company Mocon, operating with pure oxygen as permeant gas.

The tests were performed at $23^{\circ} \mathrm{C}$ with the conditioning of samples at $23^{\circ} \mathrm{C}$ with no humidity for 46 to 48 hours. The effective permeation area of each sample was $100 \mathrm{~cm}^{2}$.

The obtained results were corrected to $1 \mathrm{~atm}$ of oxygen partial pressure gradient between the two surfaces of the film, since this gradient corresponds to the driving force for permeation of the oxygen through the film.

Although the rate of oxygen permeability is characteristic of the film, the permeability coefficient was used, which characterizes the composite to minimize the effect of variation in thickness of the samples in the comparison.

The material was processed in a twin screw extruder, but the speed of $250 \mathrm{rpm}$ did not allow adequate shear and distribution of the clay particles.

Once $\mathrm{TPO}_{2}$ was determined, the oxygen permeability coefficient $(P)$ was calculated from the permeability rate as follows:

$$
P=\frac{\mathrm{TPO}_{2} \cdot e}{p},
$$

where $Q$ is oxygen permeability coefficient (mL (STP) $\cdot \mu \mathrm{m} \cdot \mathrm{m}^{-2}$ day $^{-1} \mathrm{~atm}^{-1}$ ); $\mathrm{TPO}_{2}$ is oxygen permeability rate ( $\left.\mathrm{mL}(\mathrm{STP}) \mathrm{m}^{-2} \mathrm{day}^{-1}\right) ; e$ is average thickness of the samples $(\mu \mathrm{m}) ; p$ is partial pressure of oxygen in the permeating gas chamber of the diffusion cell, because the partial pressure of $\mathrm{O}_{2}$ in the carrier gas chamber is void.

The results of the oxygen permeability coefficient are presented in Table 3.

Table 3 shows that the sample with nanoclay Cloisite $15 \mathrm{~A}$ has lower oxygen permeability coefficient, confirming the manufacturer's recommendation that indicates Cloisite 15 compatibilized with maleic acid for polyethylene due to the hydrophobicity of the polymer.

\section{Conclusions}

It is estimated that a fourth layer of carbon fiber will meet the requirements of ISO 11439:2013, supporting pressure of 495 bar for hydrostatic testing, maintaining the advantage in relation to the weight as calculated by linear regression and $(*-1)$.

It was found that, in $80 \%$ (eighty percent) of the reservoirs, the fracture of the liner, regardless of the number of layers, occurred in the region near the tops, due to lower wall thickness resulting from the manufacturing process by rotational molding, corrections being required in the project, change of materials and better control in the process to increase the strength of the liner.

Despite the difference in format between the reservoir in development and the one presented by Velosa et al. [14], there are similarities in the location of fractures resulting from hydrostatic test and the ones found in the simulation that indicated fractures near the tops, the region of highest stress.

In the case of reservoir in development, the region close to the tops has the lowest wall thickness, according to the measurements performed in the liner, requiring adjustments to the project to increase the mechanical strength of the liner in the hydrostatic test.

To increase the mechanical strength of liner and reduce the nominal wall thickness from $10 \mathrm{~mm}$ to $7 \mathrm{~mm}$, maximum thickness allowed by rotational molding, we sought new materials with rotomolded and injection molded samples.

The injected samples have higher tensile strength than the rotomolded ones, and the addition of nanoclay increases the tensile strength and the nanoclay Cloisite 30B shows better results than the Brazilian one due to the smaller particle size.

The low results obtained in the rotomolded test bodies with nanoclays are due to processing in a single screw extruder which did not allow adequate shear and distribution of the clay particles, unlike the test samples that were injected at better processing conditions.

Despite the XLPE obtaining the best result in the injected test samples, it showed the worst result as rotomolded samples, being discarded from the process for being permeable to oxygen and, by extension, to methane.

The qualitative method of selection through tensile test to evaluate the mechanical strength of the samples is justified by the application of the von Mises criterion for the flow of an ideally plastic material in a triaxial stress state, adapted to the uniaxial stress state, according to Walters.

The gas permeability is also an essential requirement for the selection of a material for the production of $\mathrm{CNG}$ reservoirs, but as it was not feasible to perform testing with methane, the main component of the CNG, we used oxygen which is compatible with it in terms of molecular diameter and polarity.

The high permeability shown by the rotomolded samples with nanoclays is due to processing in a single screw extruder which did not permit good distribution and adequate shearing of the clay particles, demonstrated by the results of permeability which increased with the addition of clay. 
The value of the permeability of the blends of polyethylene with nanoclay Cloisite 30B reached the limit of scale equipment, because the smaller the particle is, the greater the tendency it has to be grouped, facilitating the gas passages.

As for the film, the permeability coefficient was used, which characterizes the composite in order to minimize the effect of thickness variation in the comparison of the samples. The permeability coefficient characterizes the barrier of homogeneous materials, not being entirely accurate in this case.

The material was processed in a twin screw extruder, but the speed of $250 \mathrm{rpm}$ did not allow adequate shear and distribution of the clay particles, preventing the samples from becoming homogeneous.

From the data obtained it appears that the sample with nanoclay Cloisite 15A has lower coefficient of oxygen permeability.

As the pressure of the CNG reservoirs is 220 times greater than the gas permeability test performed, the values tend to increase significantly for methane reservoirs.

It was shown that it is possible to halve the volume of vehicular CNG reservoirs, maintaining autonomy equivalent to liquid fuels, by increasing the storage pressure to 636 bar, resulting in a hydrostatic test pressure of 1,431 bar according to ISO 11439:2013, 18 layers of composite to be supported, as calculated according to Formula $(*-1)$.

Therefore, the use of the reservoir in development is a viable alternative for vehicles fueled by $\mathrm{CNG}$ for it reduces the inert load, linking fuel saving to increased engine life, besides adding ecological and economic benefits to society, as well as optimizing the useful volume of the trunk by providing new formats of fuel reservoir to meet the growing range of models due to the internationalization of the car market.

\section{Conflict of Interests}

The authors declare that there is no conflict of interests regarding the publication of this paper.

\section{Acknowledgments}

The authors are grateful to IFRS, LAMEF/UFRGS, ITAL, UCS, and Xalingo for providing equipment for the testing needed for this research work.

\section{References}

[1] V. Chandra, Fundamentals of Natural Gas: An International Perspective, Penn Well, Tulsa, Okla, USA, 2006.

[2] V. Ganesan, Internal Combustion Engines, McGraw-Hill, New Delhi, India, 3rd edition, 2008.

[3] J. G. Speight, Natural Gas: A Basic Handbook, Gulf Publishing, 2007.

[4] Y. Li, J. C. Liang, W. Zhang, W. Qi, M. Su, and C. D. Liu, "Study on processs and impact strength for a rotationally molded truck fender," Journal of Materials Processing Technology, vol. 187-188, pp. 492-496, 2007.

[5] R. J. Crawford, Rotational Molding, Rapra Technology, 1993.
[6] R. J. Crawford and J. L. Throne, Rotational Molding Technology, William Andrew Publishing, 2002.

[7] F. C. Shen, "A filament-wound structure technology overview," Materials Chemistry and Physics, vol. 42, no. 2, pp. 96-100, 1995.

[8] T. Propulsion, "High-pressure conformable hydrogen storage for fuel cell vehicles," in Proceedings of the 2000 Hydrogen Program Review, San Ramon, Calif, USA, 2000.

[9] ISO 11439:2013 Gas cylinders-High pressure cylinders for the on-board storage of natural gas as a fuel for automotive vehicles, 2015, http://www.iso.org.

[10] E. P. Popov, Introdução à Mecânica dos Sólidos, Blucher, São Paulo, Brazil, 1978.

[11] E. S. Barboza Neto, L. A. F. Coelho, M. M. C. Forte, S. C. Amico, and C. A. Ferreira, "Processing of a LLDPE/HDPE pressure vessel liner by rotomolding," Materials Research, vol. 17, pp. 236241, 2013.

[12] ASTM International, ASTM F1927-Standard Test Method for Determination of Oxygen Gas Transmission Rate, Permeability and Permeance at Controlled Relative Humidity Through Barrier Materials Using a Coulometric Detector, ASTM International, West Conshohocken, Pa, USA, 2015, http://www.astm.org/Standards/F1927.htm.

[13] ASTM, "Standard test method for oxygen gas transmission rate through plastic film and sheeting using a coulometric sensor," ASTM D3985, 2010, http://www.astm.org/Standards/D3985 .htm.

[14] J. C. Velosa, J. P. Nunes, P. J. Antunes, J. F. Silva, and A. T. Marques, "Development of a new generation of filament wound composite pressure cylinders," Ciência e Tecnologia dos Materiais, vol. 19, no. 1, pp. 1-9, 2007.

[15] A. L. Brody, "Nano and food packaging technologies converge," Food Technology, vol. 60, no. 3, pp. 92-94, 2006.

[16] S. Pavlidou and C. D. Papaspyrides, "A review on polymerlayered silicate nanocomposites," Progress in Polymer Science, vol. 33, no. 12, pp. 1119-1198, 2008.

[17] M. N. Khalaf, "Control the discontinuity of the flow curve of the polyethylene by nanoclay and compatabilizer," Arabian Journal of Chemistry, 2012.

[18] M. R. Manikantan and N. Varadharaju, "Preparation and properties of linear low density polyethylene based nanocomposite films for food packaging," Indian Journal of Engineering \& Materials Sciences, vol. 19, no. 1, pp. 54-66, 2012.

[19] T. P. Mohan and K. Kanny, "Melt blend studies of nanoclayfilled polypropylene (PP) - high density polyethylene (HDPE) composites," Journal of Materials Science, vol. 48, no. 23, pp. 8292-8301, 2013.

[20] N. Saba, P. M. Tahir, and M. Jawaid, "A review on potentiality of nano filler/natural fiber filled polymer hybrid composites," Polymers, vol. 6, no. 8, pp. 2247-2273, 2014.

[21] M. Alexandre and P. Dubois, "Polymer-layered silicate nanocomposites: preparation, properties and uses of a new class of materials," Materials Science and Engineering R: Reports, vol. 28, no. 1, pp. 1-63, 2000.

[22] H. Sehitoglu, Thermomechanical Fatigue Behavior of Materials, ASTM, 1993.

[23] J. A. Walters, Hoop-Wrapped Composite, Internally Pressurized Cylinders, ASME Press, 2003.

[24] C. Borgnakke and R. E. Sonntag, Fundamentos da Termodinâmica, Blucher, São Paulo, Brazil, 7th edition, 2009.

[25] Equation, 2015, http://checalc.com/solved/naturalgasZ.html. 

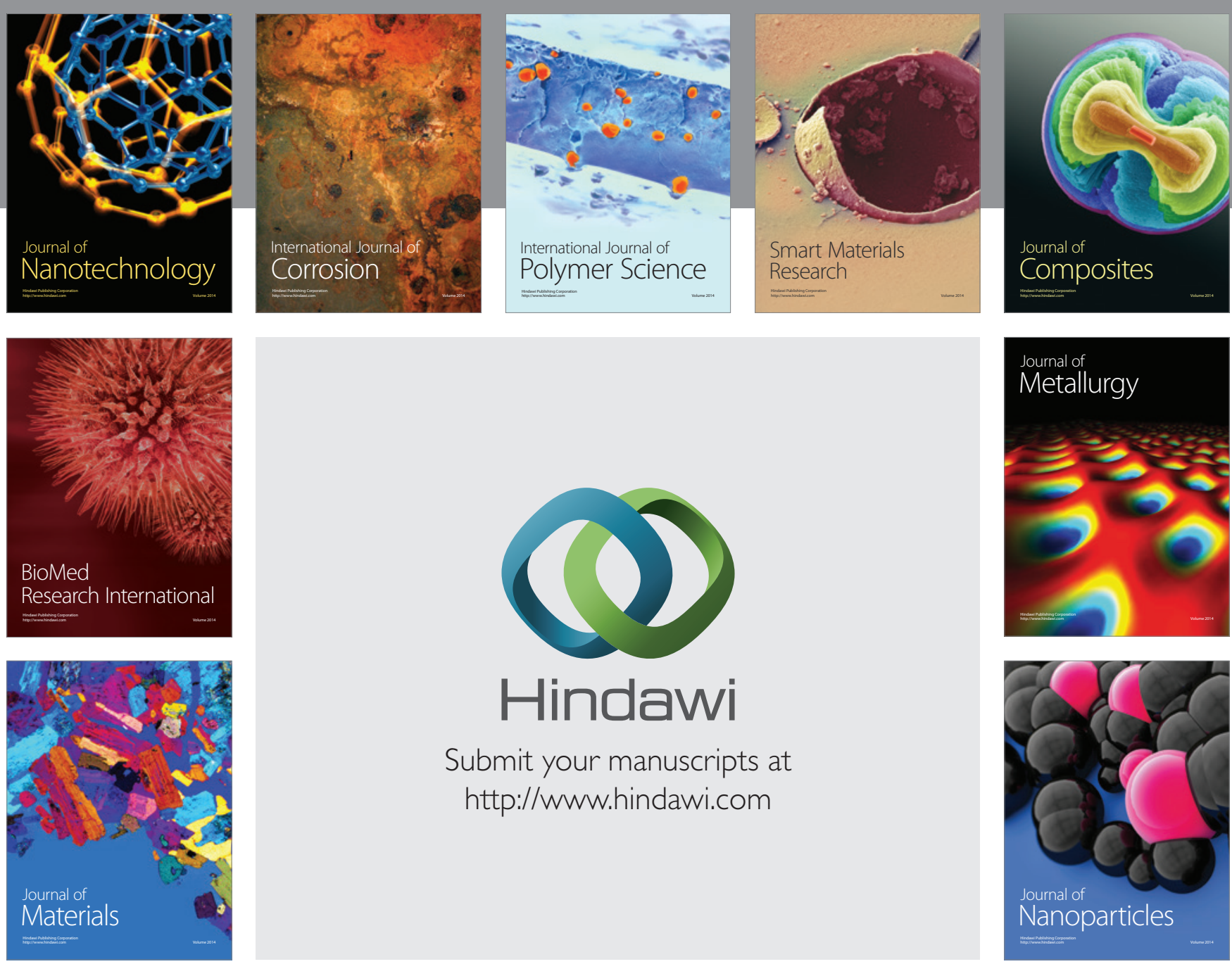

Submit your manuscripts at http://www.hindawi.com
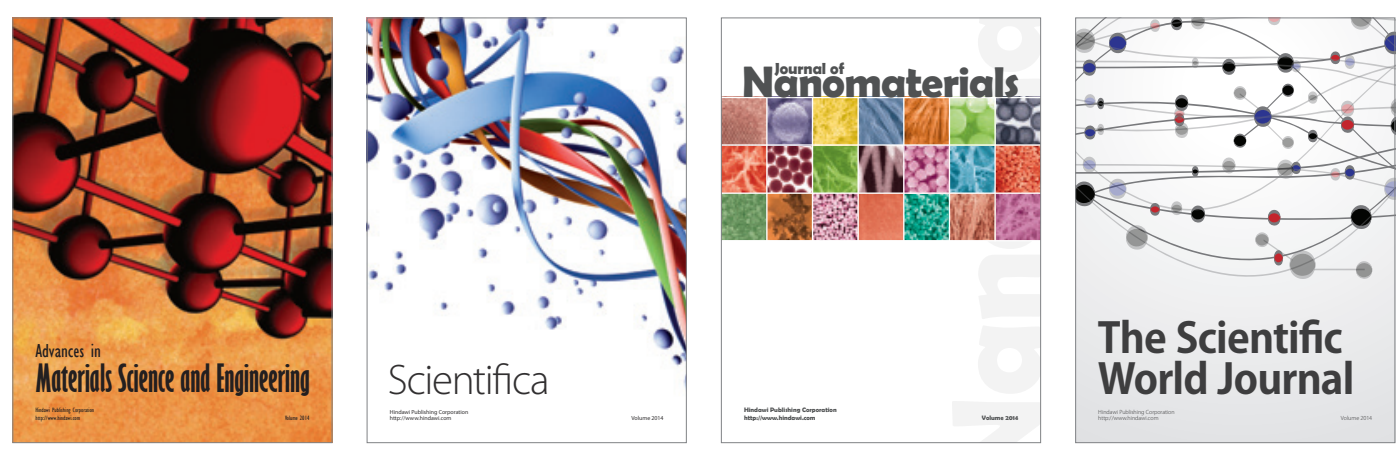

\section{The Scientific World Journal}
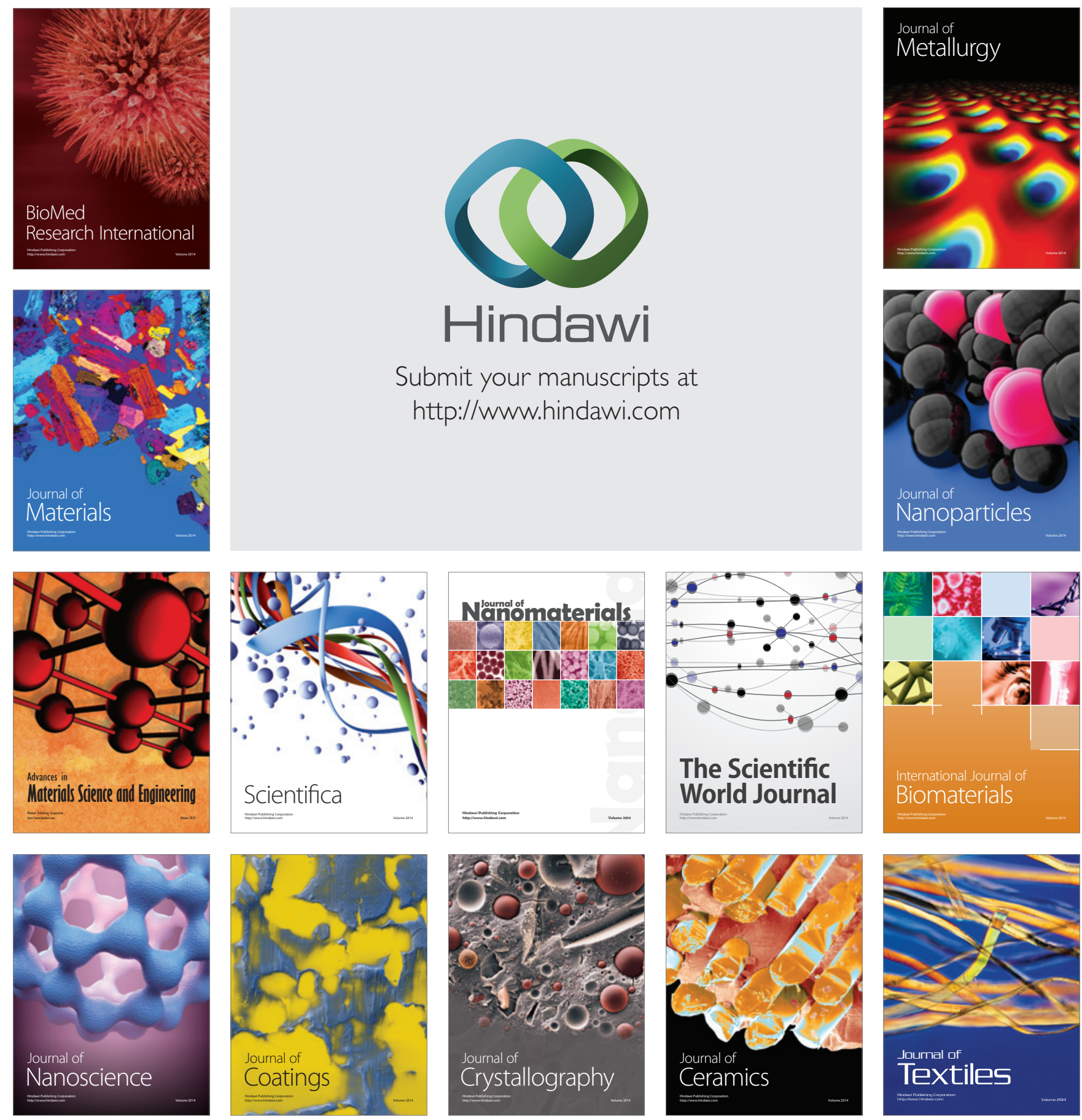